traditional modes of publication might experience feelings of anxiety.

Such anxiety seems to have prompted some taxonomists to air their concerns in print. In a paper in Zootaxa (A. Dubois et al. Zootaxa $375,1-94 ; 2013$ ), a number of disgruntled scientists take issue with the recent change, made by the International Commission on Zoological Nomenclature (ICZN) to the International Code of Zoological Nomenclature. On the surface, their argument concerns technicalities under which certain forms of publication might render nomenclatural acts 'unavailable' - that is, of no taxonomic validity. If this is indeed the case, the ICZN should take these concerns seriously with a view to amending the code to ensure that its provisions are transparent and free of contradiction. A new edition of the code is scheduled for 2018, so there is ample time for consideration.

That said, there might be more than a disinterested concern for scientific integrity at work here. A typical reader of the Zootaxa paper (not that there are typical readers of a 94-page work on the minutiae of nomenclature protocol) might reasonably conclude that the authors have axes to grind. Exhibits A-E: the high degree of autocitation in the Zootaxa paper; the admission that some of the authors were against the ICZN amendments; that they clearly feel that their opinions regarding the amendments have been disregarded; the ad hominem attacks on 'wealthy' publishers as opposed to straitened natural-history societies; and the use of emotive and occasionally intemperate language that one does not associate with the usually dry and legalistic tone of debate on this subject. (The online publisher BioMed Central, based in London, gets a particular pasting, to which it has responded; see go.nature.com/vglfig.)

One of many recommendations made in the diatribe is that journals should routinely have on their review boards those expert in the business of nomenclature - in other words, a cadre of people who are, unlike ordinary mortals, qualified to interpret the mystic strictures of the code. A typical reader is again entitled to ask whom, apart from themselves, the authors think might be suitable candidates.

The naming of species is, of course, important. There was lengthy discussion of the question of permanence, and the almost-certain

enduring nature of digital publishing, before the change to the code was made. Nature was in favour at the time and remains so today. Simply put, the positives outweigh the negatives. As we said in an editorial when the change was announced in September 2012: "It is a sensible move, and one that most in the field should welcome ... Proper taxonomy and a robust archive are crucial to science, and the zoologists were right to consider with care the possible negative aspects of such

"Given the demands on their time, the ICZNmembers could probably do without a reprisal of the online versus print naming debate." a change, as well as listening to the clamour to embrace the new." (Nature 489, 78; 2012).

It is unfortunate that the row could overshadow more cheering news from the world of nomenclature this week. The National University of Singapore has agreed to fund the secretariat of the ICZN for the next three years. As well as administering the code, the 26 volunteer commissioners of the ICZN arbitrate on disputes between scientists over the naming of the 15,000 or so species described and named each year.

Given the demands on their time, the ICZN members could probably do without a reprisal of the online versus print naming debate - a debate, remember, that saw the farcical printing to paper of hard copies of online-only papers, which were then handed to libraries to fulfil the exact wording of the code. The Zootaxa authors seem unwilling, or unable, to move on. They have a semantic bee in their bonnet over the code's requirement that species descriptions must be always "available". When the online publishers they contacted explained that, no, they did not routinely supply paper versions of the files on the journal's websites, the authors, rather uncharitably, deemed the information unavailable to them.

This year's must-have Christmas present in the United Kingdom is a miniature statue of a friend or relative, produced while-you-wait by a $3 \mathrm{D}$ printer. The technology required to make "available" a PDF file is much simpler. But then the complainants know that perfectly well already.

\section{Space spectacular}

\section{Nature doesn't usually do film reviews, but Gravity is a true great.}

$\mathrm{I}$ $\mathrm{n}$ his book An Astronaut's Guide to Life on Earth, Chris Hadfield, former commander of the International Space Station (ISS), takes aim at the empty optimism of self-help books. Never mind thinking positive, he says - the real benefits come from preparing for the worst. This philosophy is common and necessary in space flight, and so, during 'contingency sims' on the ground, NASA officials would throw a series of unexpected and unfortunate events at Hadfield and his fellow astronauts, to test their responses and to work out how they could be improved. Busy dealing with an already deadly technical threat to their lives in orbit, such as a medical emergency, the trainee spacemen and women would be told: oh, sorry, but now a fire has broken out. And by the way, you're leaking oxygen. Hadfield says he found it oddly comforting to be sitting around a table with friends and colleagues discussing, for example, how they would dispose of his corpse if he died in space.

Such a cascade of bad luck could have inspired the script of the deserved cinematic smash hit Gravity. (Yes, Nature is late to this, but the film only arrived in UK cinemas this month.) Just about everything that could go wrong for the astronauts played by George Clooney and Sandra Bullock does go wrong, so much so - and if you hate even the mildest of spoilers, then stop reading now - that when Bullock

eventually splashes back down to Earth in a remote lake, the viewer is waiting for the two-tone soundtrack and the mechanical model shark from Jaws to appear stage right.

As Colin Macilwain explores in a World View this week on page 313, Gravity is loaded with political and scientific symbolism, some subtle and some less so. The three major space-flight powers - the United States, Russia and now China - are all represented on screen, and their differing roles in the plot say much about the status of space science back on the ground in the real world.

Macilwain also celebrates the benefits the film could have for the public perception of space science, which, he summarizes, can be indistinguishable from space exploration in the public eye. Funders and scientists have quibbled for decades over the true benefit of research conducted in orbit, especially aboard the horribly expensive ISS, but there is something glorious in the fact that it is there at all.

The best stories are true, they say, and even the most spectacular film is unlikely to enthrall and enthuse a generation like the grainy pictures from the Moon landings of July 1969. Gravity is a work of fiction, and ardent science-fiction fans will argue for years over how good it really is. (The Oscar meanwhile, seems to be in the bag.) With tongues somewhat in cheeks, physicists have been picking holes in the depiction of Bullock's hair in zero gravity, and complaining about how the orbits of the space hardware seem to be aligned so conveniently for the plot.

But when you watch it, none of that matters. Gravity is a brilliant,

$\rightarrow$ NATURE.COM To comment online, click on Editorials at: go.nature.com/xhunqu dizzying, awe-inspiring and downright thrilling 90 minutes. And it will both enthuse and inspire. Go and see it on the big screen while you can. And, more importantly, take an impressionable teenager with you. 